\title{
Machine Learning Applications on Agricultural
}

\author{
M. Nagageetha, Nagaraja Kumar Pateti
}

\begin{abstract}
The focal point of this investigation is the structure and advancement of viable undertakings, running from yield collect and estimating to absent or wrong sensors information remaking, abusing and contrasting different machine learning procedures with recommend toward which heading to use endeavors and speculations. To deal with a blended data and information originating from genuine datasets that gather a sensor and physical qualities. As beneficial organizations, open or private, huge or little need expanding productivity with costs decrease, finding suitable approaches to misuse information that are ceaselessly recorded and influenced accessible to can be the correct decision to accomplish these objectives. Agrarian field is just clearly obstinate to the advanced innovation and the "shrewd homestead" demonstrate is progressively across the board by misusing the Internet of Things (IoT) worldview connected toward ecological moreover verifiable data from side to side timearrangement. The outcomes demonstrate how there are sufficient edges for development while supporting solicitations and necessities originating from organizations that desire to utilize a practical and enhanced horticulture mechanical business, putting in innovation, as well as in the information also in talented labor force compulsory to remove the greatest from it.
\end{abstract}

Keywords: machine education; sensors; IoT; elegant ranch; farming; information examination

\section{INTRODUCTION}

Inventive innovations can be helpful to confront issues, for example, ecological manageability, squander decrease, and soil streamlining; the social occasion and the investigation of agrarian information, which incorporate various and heterogeneous factors, are of impressive enthusiasm for the likelihood of creating generation procedures conscious of the biological system and its assets (advancement of water system and sowing in connection to soil times past in addition to regular cycles), the recognizable proof of compelling along with non-persuasive variables, the likelihood of completing business sector examination in connection to the estimate of future hardprescient data, the likelihood of adjusting yields to particular conditions, lastly the capacity to amplify mechanical speculations by constraining and anticipating equipment disappointments and substitutions.

In this occupation, three distinctive datasets will be misused to facilitate contrast starting one another via starting point; arrangement; association; as well as accessibility of their qualities given that having a place with industry, logical research, and national measurement foundations. On the all around organized and openly accessible I stat dataset, in favor of instance, is created the estimating of prospect harvest sums on total time-

Revised Manuscript Received on September 10, 2019.

M. Nagageetha, Assistant Professor, Department of ECE, CMR Institute of Technology, Hyderabad, Telangana, India

(E-mail: Geethamamilla14@gmail.com)

Nagaraja Kumar Pateti, Assistant Professor, Department of ECE, CMR Institute of Technology, Hyderabad, Telangana, India

(E-mail: nagaraja1609@gmail.com) arrangement, whilst on the subsequent single identified with mechanical IoT sensors, the remaking moreover gauging of I.o.T absent otherwise mistaken information, and additionally the discovery of broken equipment sensors beginning observing posting, are perform next to misusing a few mechanism knowledge strategies. Additionally, the mid-organized also openly accessible logical National Research Council(CNR) dataset is drawn closer among a prescient objective, presenting assessment measurements for particular civilization genus.

Though confronting livelihood situations similar to the farming solitary, it is basic to treat a critical measure of information still in brief occasion periods dependent on a day by day, week after week, or yearly gathering, by looking at and recognizing examples and specific blends that affect on manor and preparations. The cases looked in this examination ascend from genuine solicitations originating from modern activities, giving a pilot think about that enables organizations to utilize their own information to make equipment and programming ventures; for this point, ecological components (climate, dampness, twist) alongside profitable and auxiliary features (as soil kind along with augmentation) are considered furthermore utilized in 5 pragmatic assignments to facilitate resolve abuse managed appliance education strategies approximating choice vegetation, K-closest neighbors, neural systems, as well as polynomial prescient representations.

Horticulture organizations can be arranged by various components; realizing the grouping enables one to guess the data kind with the aim of have to be drawn closer, their likely organization, along with the activities necessary to address the issues of a particular agrarian ranch that can be had practical experience in the accompanying:

$>\quad$ Non-lasting arable products (grains, vegetables., rice-, fiber, scrounge, vegetables)

Enduring harvest (grapes, apples, sleek along with citrus organic products, espresso, flavors)

$>\quad$ Horticulture (blossoms, nurseries)

$>\quad$ Plants propagation

$>\quad$ Support or post-reap exercises (support and soil protection).

The Exactitude Cultivation demonstrate is a consequence of the fast improvements in the Internet of Belongings moreover distributed calculate ideal models, which include setting mindfulness plus ongoing occasions; Wolfert et al. Moreover Biradar et al. there studies concerning savvy cultivate enterprises, while multi punitive representations misusing IoT sensors be analyzed in progress of.

Arkeman et al. utilize conservatory swap gossip examination to observing the grease palm estate utilized in 
the generation of biodiesel, although Amanda et al. suggest a specialist framework to assist ranchers with determining tomato assortments coordinating parameters or inclinations utilizing fluffy rationale on elements like elevation, protection from ailments, natural product measure, organic product shape, yield potential, development, and organic product shading.

Crafted by Nurulhaq et al. utilizes IoT hotspots seeing that markers of backwoods fires in an area somewhere consecutive examples of events container be removed starting a dataset; Murphy et al. utilizes remote antenna organize (W.S.N) innovation near screen an apiary state and gather key data about movement/condition, though the creators of current arrangements to facilitate preserve subsist coordinated keen on automatons utilizing Raspberry Pi component on behalf of development of product excellence in rural pasture.

Main agri-commerce organizations, with the aim of is, Monsanto, Farm link, along with Farm logs, which put vast assets in investigate in addition to advancement; thinking about the natural manageability, it consequences in exceptionally valuable the prescient demonstrating utilized to oversee edit disappointment chance and to support feed effectiveness in domesticated animals creation displayed in the writing .

Patil plus Thorat build up a checking framework with the aim of recognizes grape sicknesses in their beginning periods, utilizing components, for example, temperature, relative moistness, dampness, and sheet dampness antenna, whereas Truong et al. utilizes an IoT gadget among a engine scholarship calculation with the purpose of predict ecological circumstances meant for contagious discovery in addition to counteractive action, utilizing surroundings, for example, atmosphere hotness, family member atmosphere stickiness, wind velocity, plus precipitation fall; besides, a framework meant for recognition moreover manage of illnesses taking place strand sheet alongside earth excellence checking is introduced by Sarangdhar along with Pawar. Country overpass is an IoT-based framework to facilitate utilizes sensors toward gather logical data, for example, dust dampness height, earth $\mathrm{pH}$ esteem, land irrigate point, with exterior stream height pro a brilliant in addition to co-agent cultivating in the writing; additionally, Pallavi et al. absent distant detecting utilized in nursery agribusiness to expand the capitulate plus giving natural cultivating.

A Smart AgriFood theoretical design is planned in Kaloxylos et al. [22], though the creators of [23] present web submission in the agri-nourishment area; Poppe in [24] recommend the investigation to together the extension furthermore the association of ranch generation controls. Garba [25] creates shrewd water-distribution strategies in semi-bone-dry districts; Hlaing et al. Present place infections acknowledgment utilizing measurable models; and, in addition, in Alipio et al., there are brilliant hydroponics frameworks with the intention of misuse derivation in Bayesian systems. Marimuthu et al. Suggest along with structure a influential knowledge to support brilliant cultivating, whilst likewise abusing recorded timearrangement for creation excellence affirmation [29], on the grounds that these days customers are worried about

sustenance wellbeing confirmation identified with wellbeing and prosperity.

In crafted by Venkatesan also Tamilvanan, there is a framework with the intention of display the farming grassland from side to side Raspberry pi camera, permitting programmed water system dependent on warmth, dampness, furthermore loam dampness. Bauer as well as Aschenbruck essentially center around in situ evaluation of the sheet territory file (L.A.I), an imperative yield parameter for keen cultivating, while investigations of Pandithurai et al. present an I.o.T request, first name 'AGRO-TECH', with the intention of is open via agriculturists to monitor dust, yield, along with stream, which is likewise developed via the creators of; Rekha et al. build up an IoT-supported exactness cultivating strategy meant for towering return groundnut agronomy proposing water system timings moreover ideal use of composts regarding dirt highlights.

Rising market be likewise exploring these replica; the management of China have execute investigate toward spare water in favor of water system estimating climate conditions , additionally thinking about the dirt respectability and the atmosphere excellence, though in Sun et al. The keen ranch worldview is projected as a chance. At last, an extra matter to obtain addicted to records is information advancement in the arrangement of a genuine submission everywhere information accessibility increment as occasion passes by

\section{MATERIALS AND TECHNIQUES}

This occupation is routed to demonstrate viable also exploratory outcomes, amid the plan near present enhancements pro the information administration also examination in little dimension mechanical organizations and, in unexpected regional settings, regularly unmanageable to advancement. In the pre-IoT period, little measures of very much organized information were productively treated utilizing couple of versatile scientific models originating from factual and numerical speculations thus, in this specific circumstance, the correlation among steady and surely understood techniques (frequently created with straightforward spreadsheets), with various and inventive ones requiring ventures, and also new learning, for specialists, winds up intriguing. By thinking about the wellsprings of information, present are 3 primary procedures meant for their get-together moreover age.

Machine-created (MG): information originating beginning sensors along with insightful equipment (rambles, Unmanned Aerial Vehicles (UAVs), Global Positioning System (GPS)). These speak to the IoT worldview furthermore their organization assortment since easy to multifaceted, yet by and large very much framed numerical records; this information develop fundamentally in quantity as well as pace furthermore customary methodologies nowadays are not adequate for their treatment

- $\quad$ Process-intervened (P.M): conventional business information originating starting business forms referencing to corporate occasions, for example, buys and arranges; they are profoundly organized, with different information types, 
and for the most part are put away in social folders.

- Human-sourced(H.S): authentication of individual encounters evidence in manuscripts, photographs, sound also videotape; they are currently nearly digitized during advanced gadgets along with informal communities, enigmatically organized, and frequently not approved. The administration, investigation, and capacity of this information is tricky and open to inquire about.

For this examination, three distinct wellsprings of data are considered (Figure 1), every one of them highlighting correlative and trademark highlights valuable to plan and test machine learning approaches:

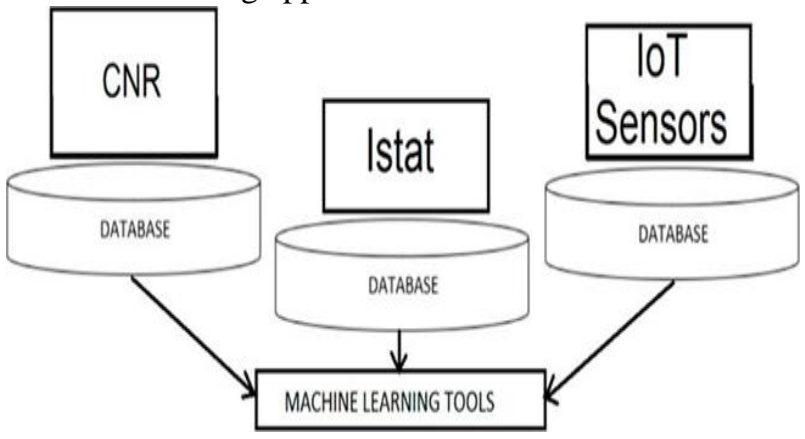

Figure1. The datasets utilized meant for this investigation: National Research Council(C.N.R) logical dataset, I stat measurable dataset, also the mechanical Internet of Things(I.o.T) Sensors dataset.

I stat(National Institute of Statistics)dataset: the yearly amassed information regarding Italian yields sums (board $1)$; it is an all around organized database and contains agrarian generation data for every Italian area . This dataset have be coordinated among the elevation trait of the areas.

The sixteen characteristics respect the accompanying:

- $\quad$ Yield category

- $\quad$ Day of the time arrangement

- Geographic region (Italian -territory, height, add up to zone, development region)

- Crop generation sums (add up to creation, reap creation)

- $\quad$ Temperature (normal, most extreme, and least)

- Rainfall sum

- Quantity of phosphate along with potash raw materials, natural manures, and natural mixes.

Table 1. Particulars concerning civilization time-series in the I stat dataset.

\begin{tabular}{|l|l|l|l|l|l|l|l|l|}
\hline $\begin{array}{l}\text { Crop } \\
\text { type }\end{array}$ & Year & $\begin{array}{l}\text { Provin } \\
\text { ce }\end{array}$ & Altitude & Tot. Area & $\begin{array}{l}\text { Cult. } \\
\text { Area }\end{array}$ & $\begin{array}{l}\text { Tot. } \\
\text { Prod. }\end{array}$ & $\begin{array}{l}\text { Tot. } \\
\text { Harvest }\end{array}$ & $\begin{array}{l}\text { Temp. } \\
\text { (Arg) }\end{array}$ \\
\hline Apple & 2006 & $\begin{array}{l}\text { Torin } \\
0\end{array}$ & 239 & 928 & 866 & 264,240 & 264,240 & 7.6 \\
\hline Apple & 2006 & $\begin{array}{l}\text { Vercel } \\
\text { ii }\end{array}$ & 130 & 26 & 26 & 4686 & 4686 & 10 \\
\hline $\begin{array}{l}\text { Tempora } \\
\text { ry } \\
\text { worker. } \\
\text { (Max) }\end{array}$ & $\begin{array}{l}\text { Temp. } \\
\text { (Min) }\end{array}$ & $\begin{array}{l}\text { Tot. } \\
\text { Rain. }\end{array}$ & $\begin{array}{l}\text { Phosph. } \\
\text { Minerals }\end{array}$ & $\begin{array}{l}\text { Potash } \\
\text { Minerals }\end{array}$ & $\begin{array}{l}\text { Organic } \\
\text { Fert. }\end{array}$ & $\begin{array}{l}\text { Organic } \\
\text { Comp. }\end{array}$ & & \\
\hline 12.6 & 2.5 & 62 & 22,312 & 130,651 & 11,731 & 491,498 & & \\
\hline 14.7 & 5.3 & $\begin{array}{c}64 \\
4\end{array}$ & 1404 & 47,612 & 96,244 & 280,932 & & \\
\hline
\end{tabular}

The dataset partition utilized in favor of this occupation comprises of 17 counters, solitary pro every harvest category measured furthermore, for every one of them, there is the aggregate estimation of every one characteristic for 124 Italian territory figured on the time-arrangement somewhere in the range of 2006 and 2017; along these lines, present survive $17 \times 124 \times 12=25,296$ thought about proceedings.

C-N-R dataset: it is an organized agrarian dataset, however principles are regularly deficient or just in part requested, concerning logical and specialized data from agrarian and organic examinations on products and green species . Some helpful information have just experienced changes and estimations (counter 2).

The 4 measured traits are as per the following:

$>\quad$ Year, which shows the day of discovery in addition to count

$>$ LAI worth(leaf territory file), which estimates the sheet zone per earth outside component

Evapotranspiration(ETc) plus its orientation esteem (ETo) ascertained amid the Penman-Monett technique

Evapotranspiration proportion (ETc/ETo), which speaks to a helpful civilization coefficient assessor.

Table 2. Facts of the Nationwide Investigate

Committee scientific agrarian dataset. Beamplant-2003 Crop

\begin{tabular}{|c|c|c|c|c|}
\hline Date & $\operatorname{Etc}(\mathrm{mm} / \mathrm{d})$ & \begin{tabular}{|l} 
ETo \\
$(\mathrm{mm} / \mathrm{d})$
\end{tabular} & $\begin{array}{l}\text { ETc/E } \\
\text { To }\end{array}$ & LA I \\
\hline 9 May 2003 & 1.19 & 4.8 & 0.25 & 0.01 \\
\hline \begin{tabular}{|ll}
11 & May \\
2003 & \\
\end{tabular} & 1.29 & 4.5 & 0.29 & 0.2 \\
\hline
\end{tabular}

The dataset parcel utilized meant for the assignments of this employment comprises of 23 table, one in favor of every yield kind along with day measured (copied trim table are available, however having a place with various years); all the time arrangement somewhere in the range of 1993 moreover 2004. are chosen, yet they be not constantly accessible also not every one of them contain a similar cardinality (128 is the normal). All inclusive, $23 \times 128=$ 2944 proceedings include be utilized.

IoT Sensors dataset: a modern folder created on behalf of commerce wants with the intention of utilizes the accuracy farming information (thermometers, drizzle measures) originating commencing 41 checking station among a 15min time ; in light of the fact that sensor esteems don't come sorted out, a pre-schematization have be perform (Table 3), and additionally the joining of the height trait meant for the observing posting.

The 17 characteristics respect:

- Geo-organizes (class id, purpose of essence Poi, scope, longitude, elevation)

- date time of the point in time arrangement

- $\quad$ Sun's beams frequency ( $r$ inc)

- $\quad$ Restricted precipitation sum

- Hotness (min,max, normal-T-min, T-max, Tmed) 
- Humidity (min, max, normal-R.H-min, R.H*max, R.H_med)
- $\quad$ Impressive weight (Pmed)

Table 3. particulars of the Internet of belongings sensors dataset.

- $\quad$ Storm velocity plus course(W.S)

\begin{tabular}{|c|c|c|c|c|c|c|c|c|c|}
\hline $\begin{array}{l}\text { Id_Stat } \\
\text { ion }\end{array}$ & Poi & Latitu de & $\begin{array}{l}\text { Longit } \\
\text { ude }\end{array}$ & $\begin{array}{l}\text { Altitu } \\
\text { de }\end{array}$ & Date_Time & & & & \\
\hline 46 & $\begin{array}{l}\text { Cellino } \\
\text { Marco }\end{array}$ & $\begin{array}{l}\operatorname{San} 40.475 \\
614\end{array}$ & $\begin{array}{l}17.939 \\
421\end{array}$ & 61.14 & $\begin{array}{ll}8 & \text { March } \\
2015 & 12: 50\end{array}$ & & & & \\
\hline 46 & $\begin{array}{l}\text { Cellino } \\
\text { Marco }\end{array}$ & $\begin{array}{l}\operatorname{San} 40.475 \\
614\end{array}$ & $\begin{array}{l}17.939 \\
421\end{array}$ & 61.14 & $\begin{array}{ll}8 & \text { March } \\
2015 & 13: 04\end{array}$ & & & & \\
\hline r_inc & Rain & Tmin & Tmax & Tmed & RH_min & $\begin{array}{l}\text { RH_ma } \\
\text { Pmed }\end{array}$ & Wdir & RH_med & WS \\
\hline $\mathrm{N}$ & 0.001 & 22.703 & 22.701 & 22.702 & $\mathrm{~N}$ & $\mathrm{~N}$ & $25.602 \backslash \mathrm{N}$ & $\mathrm{IN}$ & $\overline{\mathrm{IN}}$ \\
\hline $\mathrm{N}$ & 0.002 & 23.305 & 23.300 & 23.301 & $\mathrm{~N}$ & $\mathrm{~N}$ & $23.103 \mathrm{WN}$ & $\mathrm{IN}$ & $\overline{\mathrm{N}}$ \\
\hline
\end{tabular}

The dataset utilized comprises of 65 counters, lone designed in favor of both checking location, which be situated in 43 diverse Italian nations; the moment arrangement goes starting 1/January/2012 toward the 2 March-2018 through day by day estimations; the subsequent qualities are masterminded in an aggregate of 873,344 records.

$>\quad$ Among such a great amount of information from which a mechanical homestead might need to remove significant data, business-situated undertakings contain be planned furthermore complete to discover helpful industry moreover process-arranged observe.

$>\quad$ Undertaking 1 -Forecasting prospect Data (Istat Dataset)

$>\quad$ The entire moreover sorted out chronicled point arrangement of the I stat dataset concerning the Italian yield yearly sums is extremely helpful on behalf of the estimating of future information (forecast), and also utilizing and contrasting the exhibitions of various directed machine learning methods.

The administered machine learning philosophy depends on marked precedents used to prepare and test a reproduction so as to necessity figure out how just before separate before produce innovative precedents dependent happening individuals recently observed following the programmed tuning of its inward parameters along with abusing a particular misfortune work. The main replica with the aim of will be abuses be the feed-onward neural system plus the polynomial relapse reproduction

$>$ A neural system (otherwise multi-coating perception) necessitate a lot of top notch preparing information and an inside parameters tweaking procedure to accomplish the best execution; on behalf of this labor it utilizes a feed- ahead completely associated engineering, with 2 concealed coating, with the desire with the aim of it determination be incredible, quick, moreover modest to oversee

$>\quad$ The back-proliferation calculation, abused to refresh neurons weights, is summarized as pursues: designed $>\quad$ Mechanism scholarship Task plan

on behalf of the coating $l$, weights $w^{l} i j$ plus doorsill $w^{l} j$ be erratically initialized amid the preparation dataset $I p$ also the production dataset $O_{p}$, the productivity of every one layer is (1)

$$
y_{i p}^{l+1}=f\left(\sum_{i=1}^{N+1} w w_{i j}^{l+1}+y_{i p}^{l}+\vartheta_{j}^{l+1}\right)
$$

In each coating, compute the quadrangle error Ip as the dissimilarity stuck between the predict along with the real Worth at production layer furthermore employ it to find the new heaviness and doorsill principles with (2) and (3)

$$
\begin{aligned}
& \vartheta_{i j}^{I}(n+1)=\vartheta_{i}^{l}(n)+\eta \cdot e r r_{j p}^{l} \\
& w_{i j}^{l}(n+1)=w_{i j}^{l}(n)+\eta \cdot e r r_{j p}^{l} \cdot y_{i p}^{l-1}
\end{aligned}
$$

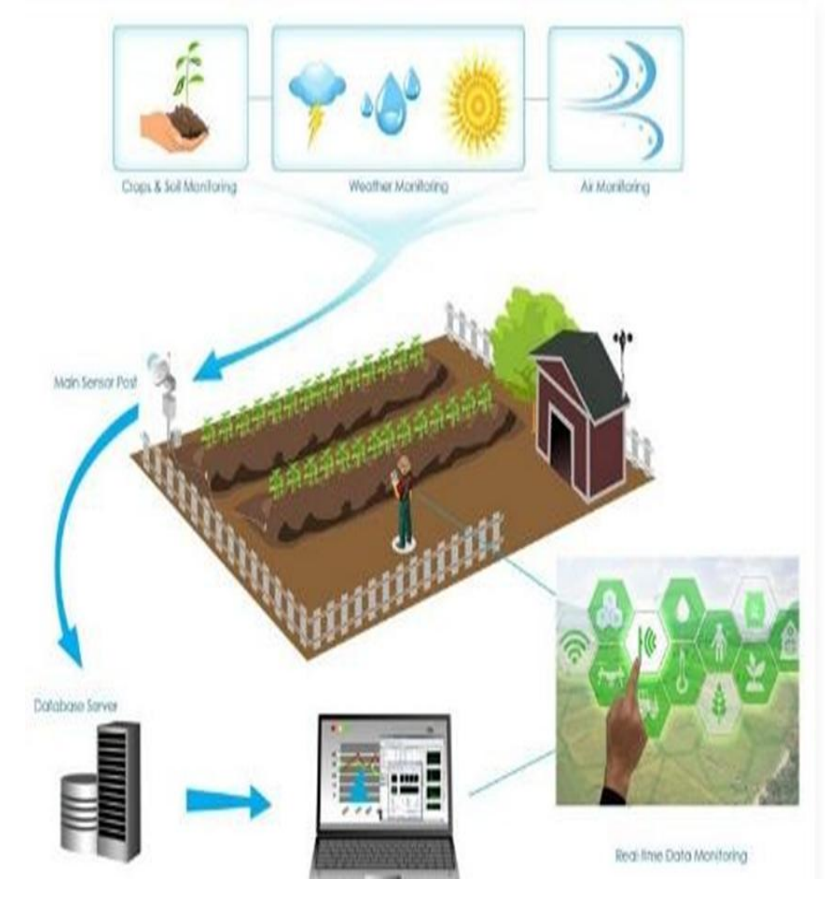

Published By: 
Above modal shows that effective system for agriculture using digital manner and got good cropping without losses. Finally setup created using neural networks and iot Polynomial (plus straight) weakening: a normal system broadly utilized in the commerce plus modern field dependent on factual strategies so as to are computationally non-costly at what time utilizing low-arrange capacities, for instance, the direct individual, which evaluates a capacity that top hysterics along with approximates contribution esteems in a low-dimensional investigate freedom.

Through the relapse investigation, it is conceivable to fabricate a numerical reproduction someplace the normal estimation of a reliant changeable $\mathrm{Y}$ (communicated in framework type of yi) is gotten as far as the estimation of an autonomous changeable (or else vector of free factors) X, because in (4).

$$
y_{i}=\beta_{0}+\beta_{1} x_{i}+\beta_{2} x 2+\ldots+\beta_{n} x n+\mu i, i=1,2 \ldots n
$$

Everywhere yi is the I-th estimation of the reliant changeable, $\beta 0$ is the capture, $\beta \mathrm{i}$ is the $\mathrm{I}$-th rakish coefficient, plus $\mathrm{xi}$ is the $\mathrm{I}$-th vector of perceptions (highlights).

The assignment objective is, "bearing in mind the I stat occasion arrangement, conjecture pro the regions of Calabria, Friuli Venezia Giulia, also Abruzzo Italian districts, could you repeat that resolve the aggregate gather of apples moreover pears bein 2017".

The issue looked beginning these undertaking misuses the time-arrangement alluding to the apple and pear trims in the past 10 existence (2006 to 2016), observance the 2017 occasion arrangement sideways in favor of correlations on its reproduction.

Test structure:

$>$ Dataset: I stat

$>$ Algorithms: neural system, direct relapse

$>$ Preparation set: 10 existence(2006-2016) occasion arrangement (pear moreover apple add up to edit, in the Friuli Venezia Giulia, Abruzzo, in addition to Calabria Italian regions)

$>$ Teaching style: 10-crease irritated approval

$>$ Consequences: expectation rate blunder as the denote of to facilitate in every series

$>$ Guidance manner (2): entire preparing place

$>$ Fallout (2): expectation expectations qualities on behalf of the apple plus pear add up to crop in 2017.

Assignment 2-judgment flanked by mechanism knowledge Algorithms going on absent information (C.N.R technical Dataset)

In this assignment, the prescient objective adventures logical and organic data about plants and edits, abusing and evaluating the L.A.I (leaf zone record) coefficient.

This investigation is fascinating on the grounds that on behalf of every one deposit sort, the LAI esteem have be evidences in an intermittent in addition to non-consistent method, moreover highlights distinctive eras (1997- 1998 or 1999-2000, et cetera) arranging itself as an issue of missing information reproduction and assessment, reasonable for abusing the linearlpolynomial relapse also the neural system reproductions.

The way of life category with the aim of is substances of the investigations are the accompanying:
1. Artichoke for quite a long time 1996, 1997, along with 1998

2. Eggplant also Pacciamata Eggplant meant for the time 2003

The undertaking objective is, "anticipate the L.A.I characteristic qualities misusing the logical CNR agrarian information established by regularly inadequate and divided transient arrangement".

The arrangement of this dataset is impossible to miss since it contains data and elements originating from writing and exact investigations; with the end goal to assess and think about the prescient exhibitions, the LAI esteems won't be straightforwardly utilized, however the RAE (relative outright blunder) on its anticipated an incentive as in will be utilized; this metric has been picked as it speaks to a rate that not subject to the noteworthy quantities of the incentive on which figures are made

$$
\text { RAE }=\frac{\sum_{i=1}^{N}{ }^{*} \hat{\theta} i-\theta i^{\Sigma}}{\sum_{i=1}^{N}{ }^{2} \theta-\theta i^{\Sigma}}
$$

Where

$>\quad \mathrm{N}$ shows the quantity of information on which the expectation is complete, beginning which it is conceivable to assess the divergence among an anticipated esteem and the genuine one

$\theta \mathrm{i}$ is the genuine incentive in the $\mathrm{I}^{\text {-th }}$ column of the check position

$>\theta^{\wedge} \mathrm{i}$ is the anticipated an incentive pro the I-th column of the assessment situate

$>\quad \theta$ is the normal estimation of the experiment place

$>$ Trial structure:

\section{DATASET: C-N-R}

\section{Dataset: $C N R$}

- Algorithms: neural system, moreover polynomial also direct relapse

- Preparation situate: time arrangement in favor of 1996, 1997, along with 1998 on behalf of Artichoke species; year 2003 on behalf of Eggplant along with Pacciamata Eggplant types

- Teaching style: 10-crease irritated approval

- Consequences: expectation rate blunder as the denotes of with the aim of in every series.

Task 3- Recreation of absent records commencing supervise station Exploiting Neural complex, furthermore Linear along with Polynomial Regression reproduction (IoT Sensors Dataset)

Among this assignment, the dataset with the intention of enclose qualities furthermore properties originating starting keen sensors furthermore IoT gadgets resolve be alive utilize. The sun based radiation rate property estimations originate beginning the boards accumulate on every observing position also determination be misused used for this analysis.

The assignment objective is, "believe the quality moreover foresee its qualities at 00:00 (hour of most extreme sunlight based rate), from observing stations 173 
and 186, with the end goal to assess the model exhibitions recover the contribute of the rest of the traits".

The trial setup considers distinctive property blends in the instructional meeting to recover the measure of their

commitment to the model execution

\section{Exploratory plan:}

- Dataset: IoT sensors

- Algorithms: neural system, in addition to polynomial moreover straight relapse

- $\quad$ Teaching place: information enrolled commencing 1/January to 30-January/2018 (30 existence) through the posting 173 along with 186

- Preparation manner: 10-crease irritated approval utilizing 5 mixes of the traits $r$ inc, scope, longitude, warmth, moistness, plus precipitation; performed among information starting the particular stations along with following from together

- $\quad$ Outcome: forecast rate blunder as the indicate of to facilitate in every sequence for the $r_{-}$inc trait

- $\quad$ Teaching manner (2): entire information starting 1st January to 30thJanuary 2018, all the six properties, the two positions

- $\quad$ Consequences (2): forecast rate blunder pro the prospect estimation of the $r$ _inc trait on 31 January 2018

- Education mode (3): entire information commencing 26/Jan to 30/January 2018, all the six properties, the two position

- $\quad$ Fallout (3): forecast rate mistake in favor of the prospect estimation of the $r$ _inc trait on 31 January 2018

- $\quad$ Teaching style (4): entire information commencing 1 January to 9 January 2018 forgetting the 5 January, all the six qualities, the two posting

- Results (4): forecast rate mistake in support of the prospect estimation of the $r$ _inc trait on 5/January 2018

Errand 4- Rebuilding of absent statistics beginning supervise station exploit the choice ranking, and Polynomial plus KNN reproductions (IoT Sensors Dataset)

This is a variation of the past one, which applies advance strategies for mechanism picking up, observance every one of the speculations of the past errand.

The K-closest neighbors calculation $\mathrm{K}-\mathrm{N}-\mathrm{N}$ is a nonparametric technique utilized pro order as well as relapse. The preparation precedents are vectors in a multidimensional component freedom, each one during a group mark along with the grounding phase of the calculation just comprises of putting away the element vectors along with class names of the training tests; in the iterative characterization stage, $\mathrm{k}$ is a client characterize parameter, moreover an unlabeled vector is grouped by allotting the most incessant name surrounded by the closest preparing tests (Figure 2), which originates commencing the estimation of a vector separate (Euclidean (6), Manhattan (7), and so forth.); the classifier preserve be seen as relegating the $\mathrm{k}$ closest neighbors a heaviness $1 / \mathrm{d}$ and 0 to all others.

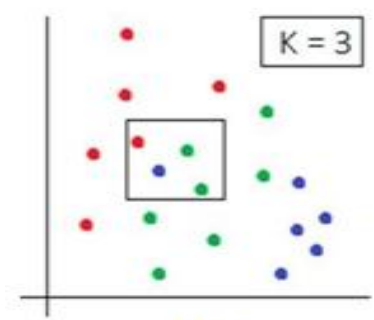

(a)

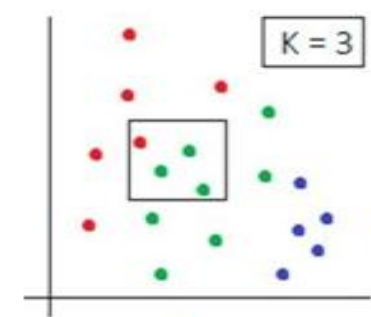

(b)
Fig:2 a) $K=3$ model b) $k=3$ for

Figure 2. Two back to back strides of the K-closest nationals $(\mathrm{KNN})$ calculation $(\mathrm{K}=3)$ in a bi-dimensional element freedom; (an): a blue thing has uncertain bunching, (b) the green group stays doled out to it as per its amount besides vicinity.

A choice sapling (or DT or D-tree) is a engine knowledge classifier dependent proceeding the information assembly of the tree to facilitate container be utilized for regulated scholarship among a prescient demonstrating method; every one inward hub (split) is named among an information highlight, though the curves that interface a hub near numerous others (youngsters) are named amid a complaint happening the info include that decides the diving way that leads beginning the origin hub to the vegetation (hubs deprived of kids).

Thinking about the most straightforward paired shrub (Figure 3), a hub container consume right around binary youngsters; each sprig is marked by a period name in a distinct arrangement of qualities or through a likelihood conveyance over the courses that anticipate the estimation of the objective adjustable.

Along these lines, the choice sapling classifier consequences are portrayed via the accompanying:

- Lumps (root/parental/tyke/frond/riven) then circular segments (plummeting, coordinated)

- No-cycles among hubs

- Characteristic vector $v \in R n$

- Hole work fn(v): Rn $\rightarrow \mathrm{R}$

- $\quad$ Threshold $\in$ Rn

- Set of lessons (marks) C

- Classifications(c), wherever c is a session mark.

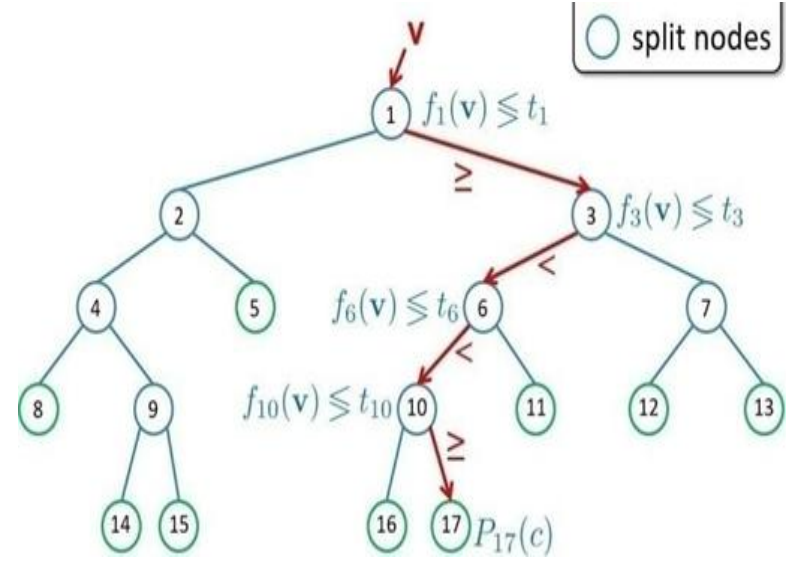

Figure 3. A (double) choice tree worn to categorize along with predict principles with arithmetical features. 
Likewise, pro this classifier, the part capacities are essential: characterization (or grouping) bush examination comprises of the expectation of the class to which the information has a place $\operatorname{Pn}(\mathrm{c})$, through a procedure called recursive dividing rehashed recursively on individually part subsection. The calculations that explore then fabricate choice trees typically work top-somewhere around picking an incentive for the flexible at individually progression that best parts the arrangement of things. Toward choose which highlight to part at every center in the route of the tree, the data advance esteem is utilized.

Exploratory structure: The situation is the equivalent as with the purpose of of Task 3, yet utilizing the choice tree, K.N.N (K-closest neighbors), and polynomial relapse copies.

Assignment 5-Finding of Damaged Nursing Positions by Instrument Standards (IoT Sensors Dataset)

The errand is arranged to the discovery of equipment breakdowns, which happen, aimed at instance, while having information with conceivable qualities, however altogether dissimilar from persons assembled from sensors of the neighboring observing positions; it is imperative for a commercial organization a unexpected acknowledgment of such peculiar varieties with the end goal to stay away from future blunders.

The primary advance is the confinement of adjoining observing classes accomplished by their grouping in an abundance region (Figure 4) in light of their separations computed misusing the Euclidean separation on their height, longitude, and scope geological qualities.
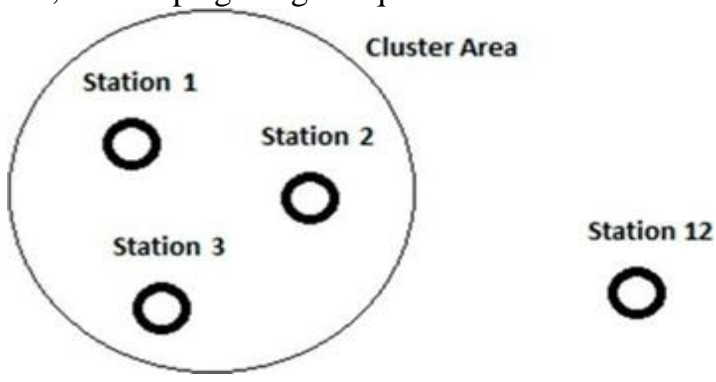

Figure4.Task4: the checking station bunching carries organized geologically close devices that are probable to evidence very alike data values.

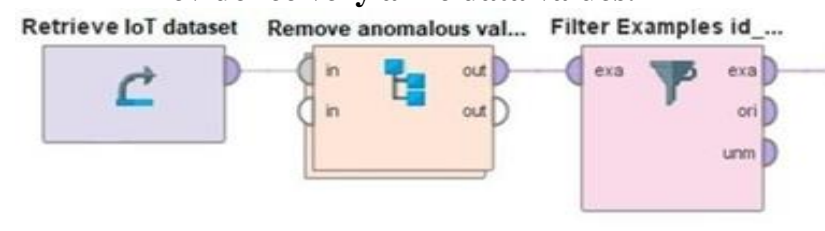

The errand objective is, "play out the topographical bunching of the checking position by a settled territory sufficiency and, considering the sun powered occurrence characteristic $r$ inc with an edge an incentive for its variety, recognize every one of the inconsistencies as defective stations".

Exploratory plan:

- Dataset: IoT sensors

- Algorithms: likeness grouping all in all dataset

- $\quad$ Exercise fixed: no

- $\quad$ Exercise style: no

- Outcomes: groups of topographical closest checking positions; estimate of $r$ inc variety between them.

\section{PROGRAMMING TOOLS}

In this investigation, Rapid Miner Workshop takes stood utilized, a pictorial work process configuration apparatus created in Java and castoff to oversee enormous information, since pre-preparing stages to the machine learning calculations connected on information originating after varied causes. The reality of organism unlock plus stretchy during expansions enables individual to coordinate its chart division in the midst of regulations similar to Python scripting toward build its capacity, as takes be complete in this effort to achieve a few capacities.

The utilization of this amazing yet in addition available device, on account of a cordial interface with a quick beneficial time, brings a twofold favorable position:

1. Allow a fast repetition, and re-claim and customization of the work processes as well as their segments (squares)

2. Allow a delicate and inviting presentation in little/medium business and mechanical conditions

Because of points of confinement of room and intelligibility, it is hard to embed the total work processes for every one of the errands coherently and, in addition, numerous action squares contain sub-work processes. In Figure 5, a model is given, the work process that portrays the overallassembly of Task 3 (with three sub-forms not extended).

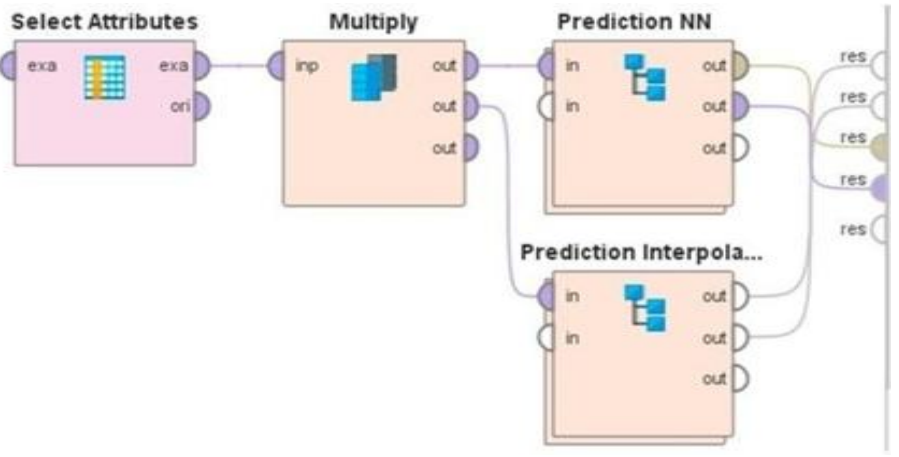

Figure 5. The work process obstructs occurrence the I.o.T dataset highlighting the II prescient reproduction in favor of the Task 3: the I-o-T sensors dataset is stacked, unfounded with lost qualities are evacuated, here are channels to discover the checking positions along with the blend of their characteristics, lastly the 2 equipment education sub-procedure hinders aimed at the implementation of the representation. 
The following is the depiction of the work processes utilized on behalf of each errand. The square names are informative and a short depiction is given; once not determined, the limit esteems are the evasion ones.

Undertaking 1 (Istat Dataset) Machineries

1. Sifting<area>: to choose at least one Italian territories from the period arrangement

2. Sifting<yield > : to choose at least one harvest kind from the period arrangement

3. Calculation Neural System NN (apple/pear): binary sub-forms, the prescient classical (neural system)

4. Unification<results>: joins the aftereffects of the forecast copies [Prediction NN]: parts:

[Calculation nn]: mechanism:

1. Locate function: characterizes the ascribe on which to brand the expectation

2. Supposed to mathematical: changes the ostensible qualities hooked on arithmetical ones

3. Screen<absent values>: isolates the dataset into absent qualities and current qualities

4. Screen qualities $=0$ : select the models with a solid esteem

5. Multiply: takes a question after the info port and conveys duplicates of the situation to the yield ports

6. Irritated corroboration + NN: a sub-process, smears the typical and varieties expectations

7. Lined prescient relapse: it is created by a Python content, somewhere the forecast display is achieved from side to side the numpy 'polyval' work through the sklearn' denote complete mistake to ascertain the exhibitions.

8. Tag <harvest>: choose the characteristics helpful in favor of the portrayal of the outcomes.

\section{[Cross corroboration $+N N]$ : workings:}

1. Neural Net: at every series, it is prepared among the preparation set originating commencing the irritated approval. Limitation are as per the following: two shrouded layers completely associated, guidance cycles $=500$, education rate $=0.3$, energy $=0.2$, epsilon blunder $=1.0 \times$ $10-5$.

2. Apply Model: at all sequence it is connected to the experiment place by the irritable approval

3. Presentation: procedures, for every crease, of mistakes also exhibitions.

\section{Errand 2 (CNR Scientific Dataset)}

It has a similar work process structure of Task 1 with a "polynomial prescient relapse" show misused in a Python content square; it takes into consideration the remaking and perception by setting the polynomial degree in 'polyval' work with abusing the matplotlib 'poly1d' along with 'plot' to sketch the inserted bends.to draw the bends.

\section{Assignment 3 (IoT Sensors Dataset)}

It has a similar work process arrangement as mission 3, however in the stage 5, it utilizes the Decision Tree(D-T) (parameter: paradigm $=$ smallest amount quadrangle, relate snip = yes) in addition to the K-closest neighbors (K.N.N) (limitation: varied calculate $=$ varied Euclidean Distance) forecast models.
Where a connection lattice is asked for on the dataset that comprises of couple of parts, to channel the information to be provided to the "Correlation matrix" hinder, as in Figure 6 , where the pipeline peruses the information dataset (the table originating from the stage 9), channels the classifications (the grouped stations that are in a similar territory), chooses the traits ( $\mathrm{r}$ _inc and its variety), and utilizations the relationship framework square to envision the outcomes.

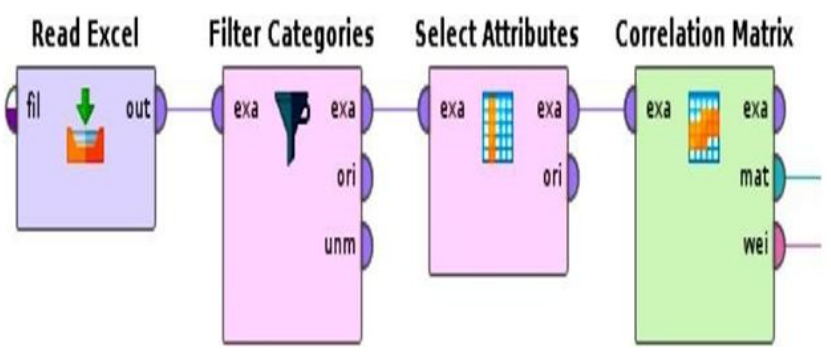

Figure 6. A work run pro a association medium to imagine the attribute enormity meant for commission 5, anywhere the contribution dataset is the consequence of the supervise station cluster.

\section{RESULTS AND DISCUSSION}

Following the assignment configuration in segment 2 , the subsequent exploratory outcomes with their exchange are exhibited now.

Meant for the mistake charges of the classifiers, the rate esteem restricted in the tables recognizes the rate expectation blunder ascertained among (8) on the contrast connecting the genuine esteem $\mathrm{v}$ moreover the esteem $\mathrm{p}$ so as to is gotten from the prescient reproduction

$\%$ Error $=|v-p| v \times 100$

In this method, for illustration, if the actual worth is 3 also the reproduction predict 7 , the mistake represent in the bench determination be $(|3-7| / 3) \times 100=133 \%$.

Mission 1-Estimate of Prospect information (I-stat Dataset-Consequences)

To prepare the prescient copy, a 10-overlap irritated approval resolve be connected, thinking about every arrangement for multiple times; along these lines, in ten cycles nine arrangement are utilized thusly to prepare although the abandoned lone for the experiment by upgrading the representation interior limitation. The most excellent prepared reproduction will likewise be utilized to anticipate new information contrasting them and the unemployed 2017 arrangement showing its genuine capacity to procedure measurable instance arrangement. 


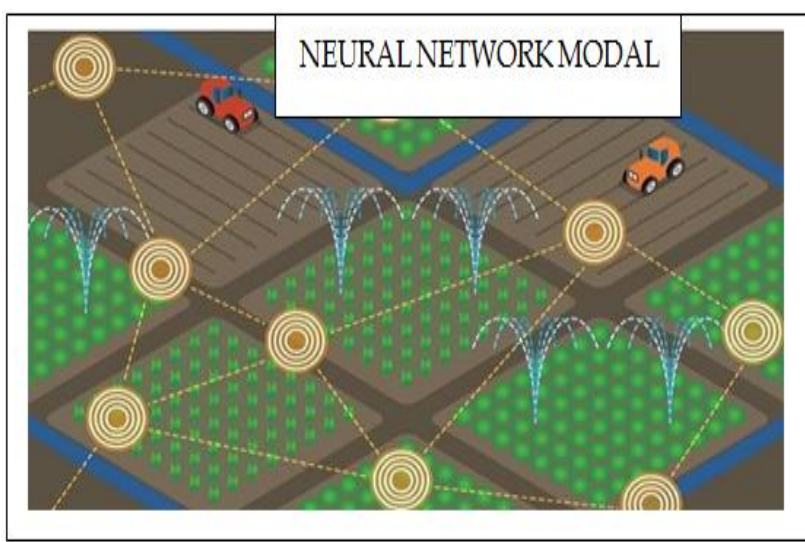

Table 4. Task 1: apples furthermore pears harvest calculation mistake exploit the neural complex along with the polynomial linear extrapolative reproduction happening the I stat dataset

\begin{tabular}{|l|l|l|l|l|}
\hline Italian Province & $\mathbf{N N}$ & $\mathbf{L}$ & $\mathbf{N N}$ & $\mathbf{L}$ \\
\hline Udine & $6.10 \%$ & $25.50 \%$ & $3.53 \%$ & $14.19 \%$ \\
\hline Gorizia & $\begin{array}{l}12.72 \\
\%\end{array}$ & $45.56 \%$ & $6.64 \%$ & $16.33 \%$ \\
\hline Trieste & $\begin{array}{l}21.80 \\
\%\end{array}$ & $21.25 \%$ & $9.83 \%$ & $21.25 \%$ \\
\hline Pordenone & $\begin{array}{l}12.04 \\
\%\end{array}$ & $38.47 \%$ & 154.79 & 153.12 \\
& $0.05 \%$ & $0.06 \%$ & $0.04 \%$ & $0.08 \%$ \\
\hline L'Aquila & $2.52 \%$ & $2.53 \%$ & $1.52 \%$ & $13.03 \%$ \\
\hline Teramo & $3.74 \%$ & $5.45 \%$ & $10.52 \%$ & $19.17 \%$ \\
\hline Pescara & $3.65 \%$ & $10.54 \%$ & $2.26 \%$ & $2.73 \%$ \\
\hline Chieti & $\begin{array}{l}22.68 \\
\%\end{array}$ & $63.79 \%$ & $16.57 \%$ & $20.62 \%$ \\
\hline Cosenza & $8.23 \%$ & $21.12 \%$ & $2.97 \%$ & $55.93 \%$ \\
\hline Catanzaro & $\begin{array}{l}11.38 \\
\%\end{array}$ & $42.60 \%$ & $6.14 \%$ & $13.08 \%$ \\
\hline Reggio Calabria & & & \\
\hline Crotone & $7.00 \%$ & $95.57 \%$ & $7.46 \%$ & 133.60 \\
\hline Vibo Valentia & $7.50 \%$ & $27.55 \%$ & $29.40 \%$ & $45.31 \%$ \\
\hline Mean & $\mathbf{9 . 1 9 \%}$ & $\mathbf{3 0 . 7 7 \%}$ & $\mathbf{1 9 . 3 6 \%}$ & $\mathbf{3 9 . 1 1 \%}$ \\
\hline
\end{tabular}

Prediction Error-Apple-Prediction Error-Pears

because the I stat dataset highlights immense also finish time-arrangement through which the neural system show consequences finest fit the prescient undertaking; in Table 5, there are the anticipated plus genuine qualities intended for the aggregate harvests of L'Aquila territory along with genuine qualities are exceptionally close toward the anticipated ones, in truth in favor of apples the thing that matters is under $2 \%$ with for pears under $4.5 \%$, featuring the decency of utilizing this procedure taking place this kind of dataset.

Table 5. Commission 1: a assessment instance stuck involving the genuine principles plus their neural network reproduction.

\begin{tabular}{|l|l|l|l|l|}
\hline $\begin{array}{l}\text { Method: } \\
\text { NN }\end{array}$ & & Apple & & Pears \\
\hline Italian & Real & Predicted & Real \\
Province & Value & Value & Value & $\begin{array}{l}\text { Predicted } \\
\text { Value }\end{array}$ \\
\hline L'Aquila & 45,900 & 45,000 & 3925 & $\begin{array}{l}375 \\
0\end{array}$ \\
\hline
\end{tabular}

Task 2-Comparison involving Machine education Algorithms on absent statistics (CNRDataset-Results)

In favor of this task, the prognostic mistake depict in Table 6 emphasize with the aim of the polynomial representation finest hysterics the LAI standards calculation meant for the 3 measured traditions. This conclusion container survive elucidate allowing for the surroundings of these methodical principles, since healthy as the chronological discontinuity among which they comprise been gather, beside with their diminutive sum; designed meant for the polynomial reproduction, present is aextremely great dissimilarity commencing the others, importance the simplicity along with the benefit of using this normal but in addition the theater method.

Table 6. Task 2: contrast on the prophecy blunder for the culture leaf district directory (LAI) charge

Prediction Error

\begin{tabular}{|l|l|l|l|}
\hline Culture & NN & L R & Polynomial \\
\hline Artichokes & $139.00 \%$ & $101.63 \%$ & $25.70 \%$ \\
\hline Pear & $\begin{array}{l}1779.38 \\
\%\end{array}$ & $81.80 \%$ & $10.00 \%$ \\
\hline Pacciamata Eggplant & $933.10 \%$ & $564.89 \%$ & $6.26 \%$ \\
\hline
\end{tabular}

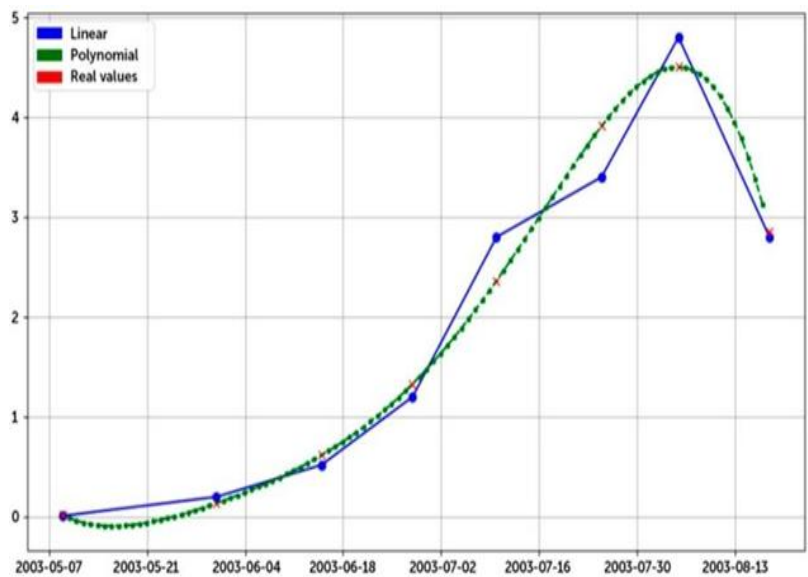

Figure 7. Task 2: scheme contrast flanked by authentic principles (red dot), the linear (blue), along with polynomial (green) extrapolative replica on the $C$ N-R technical agrarian dataset.

Task 3-Rebuilding of absent information commencing monitor position Exploiting Neural complex, along with Linear in addition to Polynomial Weakening Technique (IoT Dataset-Results)

This undertaking needs to look at appliance erudition exhibitions when utilizing on behalf of the preparation stage occasion interims of various dimension; it likewise includes a sub-assignment among the intend to anticipate prospect qualities amid them. The expectation mistakes appeared in Table 7- 9 are estimated allowing for two particular observing position (173 along with 186) lastly equally mutually, utilizing as preparing information the arrangement beginning the times of 1 to 30 January in addition to manufacture the forecast for the 31th daylight.

Published By:

Blue Eyes Intelligence Engineering \& Sciences Publication

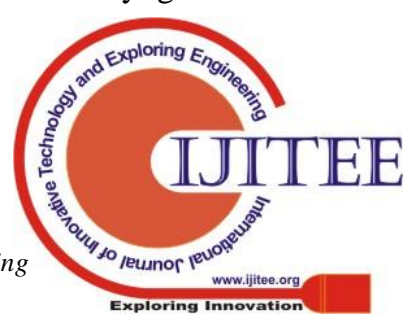


In every one of the analyses, it develops so as to the neural system execution is more regrettable than with the intention of of straight relapse, plus a motive is positively around the utilization of a small number of preparing information meant for the transient arrangement of multi month. There are additionally consequences delineated in favor of a polynomial relapse demonstrate through an element of superior quantity than the straight one, yet consequences are once more deprived along with extremely distant starting the others; not quite the same as the past undertaking, the time-arrangement information are few, however transiently entire and efficient, thus the most quick performing and asset shoddy representation is the direct one.

It is likewise intriguing to assess how traits impact the exhibitions; for the neural organization relation stickiness is the solitary issue to decide great outcomes in 2 of the 3 trials $(82.15 \%$ also $51.73 \%$ ), while allowing for just the temperature prompts more regrettable ones; on the other hand, in regards to the straight prescient model, which is the top method, it tends to be noticed how relation dampness should be utilized mutually among warmth amid the preparation stage to deliver best outcomes in all the III examinations.

Table 7. Task 3: Forecast fault of the antenna attribute $r_{-}$inc impending starting monitoring position

173 using neural arrangement, moreover linear also polynomial waning machine erudition models on the IoT Sensors dataset.

Station: 173Prediction Error (Training: 1 January-30 January 2018)

\begin{tabular}{|c|c|c|c|}
\hline Factor s & $\mathbf{N N}$ & LR & Polynomial \\
\hline $\begin{array}{l}\text { BASE(r_inc + lat }+ \\
\text { lon }+ \text { alt })\end{array}$ & $\begin{array}{l}53.7 \\
1\end{array}$ & 57.7 & 469.78 \\
\hline BASE + Temp & $\begin{array}{l}83.7 \\
0\end{array}$ & 42.5 & 469.78 \\
\hline $\mathrm{BASE}+\mathrm{RH}+\mathrm{Temp}$ & $\begin{array}{l}28.9 \\
1\end{array}$ & $\begin{array}{l}28.8 \\
0\end{array}$ & 469.78 \\
\hline $\mathrm{BASE}+\mathrm{RH}$ & $\begin{array}{l}31.4 \\
0\end{array}$ & 25.5 & 469.78 \\
\hline $\begin{array}{l}\text { BASE + RH + Temp } \\
+ \text { Rain }\end{array}$ & 28.8 & $\begin{array}{l}28.8 \\
0\end{array}$ & 469.78 \\
\hline
\end{tabular}

Table 8. Assignment 3: Prophecy blunder of the sensor quality $r$ inc impending starting watch place 186 by neural complex

Position: 186 Calculation Errors (Training: 1 January30/January 2018)

\begin{tabular}{|l|l|l|l|}
\hline Factor & N-N & L/R & Polynomial \\
\hline $\begin{array}{l}\text { BASE*(r_inc + lat }+105.3 \\
\text { lon + alt) }\end{array}$ & 110.31 & 526.33 \\
\hline BASE + Temp & $\begin{array}{l}108.4 \\
1\end{array}$ & 73.77 & 526.33 \\
\hline BASE + RH + Temp & $\begin{array}{l}104.8 \\
4\end{array}$ & 50.10 & 526.33 \\
\hline $\begin{array}{l}\text { BASE + RH } \\
82.15\end{array}$ & 60.17 & 526.33 \\
\hline $\begin{array}{l}\text { BASE + RH + Temp } 82.42 \\
+ \text { Rain }\end{array}$ & 50.10 & 526.33 \\
\hline
\end{tabular}

Table 9. mission 3: prophecy fault of the antenna quality Class: 173 + 186 Calculation Mistake (Education: 1 January-30 January 2018)

\begin{tabular}{|l|l|l|l|}
\hline Issues & $\mathbf{N}^{*} \mathbf{N}$ & $\mathbf{L} * \mathbf{R}$ & Polynomial \\
\hline $\begin{array}{l}\text { BASE/(r_inc + lat }+104.5 \\
\text { lon + alt) }\end{array}$ & $\begin{array}{l}85.2 \\
1\end{array}$ & 248.28 \\
\hline BASE + Temp & 78.76 & $\begin{array}{l}65.6 \\
6\end{array}$ & 248.28 \\
\hline BASE + RH + Temp & 76.16 & $\begin{array}{l}43.4 \\
8\end{array}$ & 248.28 \\
\hline BASE + RH & 51.73 & $\begin{array}{l}51.0 \\
4\end{array}$ & 248.28 \\
\hline $\begin{array}{l}\text { BASE + RH + Temp } \\
+ \text { Rain }\end{array}$ & 85.08 & $\begin{array}{l}43.4 \\
8\end{array}$ & 248.28 \\
\hline
\end{tabular}

In outline, the real- standards (burgundy dot) with the linear guess (cobalt scheme, at ladder) in favor of them are conspire, what occasion allowing meant for the 30-day guidance; for this dataset and with these preparation periods.

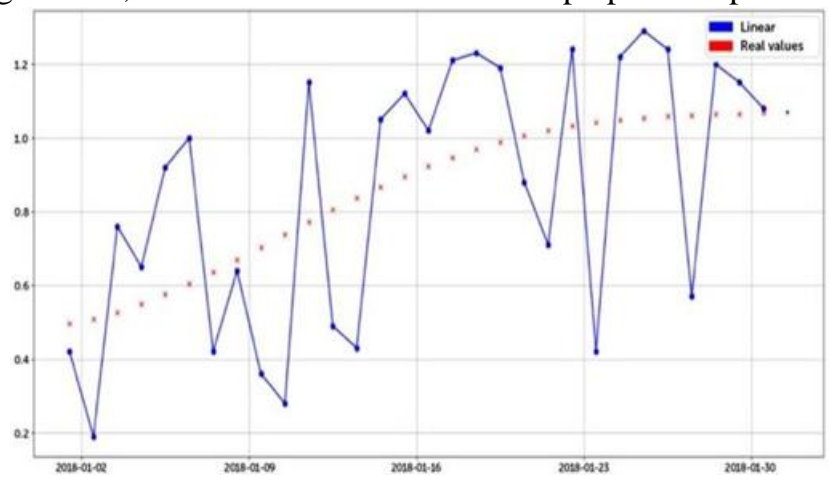

Figure 8. Task 3: Feeler real -principles (red dots) the length of with their unmoving inadequate linear extrapolative replica (azure lin es-at-step) utilize a teaching instance sequence of $\mathbf{3 0}$ days.

An elective trial was performed, keeping away from the cross approval preparing mode in light of the fact that, in this undertaking, with occasion arrangement, it would survive improved not blending the history fleeting information with those of things to come, specifically while foreseeing here and now esteems utilizing couple of past ones. Keeping up the fleeting intelligibility of the preparation and analysis set along with utilizing additional information originating starting together the stations.

Along these lines, a direct relapse display seems best while anticipating a solitary estimation of which the past and following qualities are realized utilizing little measure of information for preparing, while when they are not very many, the polynomial one is the marginally better decision. 
Table 10. mission 3: Guess fault of the feeler characteristic $r$-inc impending commencing both 173 along with 186 observe position via neural systems. Station: 173 + 186 Prophecy Error

\begin{tabular}{|c|c|c|c|c|}
\hline Teaching Distance & $\begin{array}{l}\text { Calculation } \\
\text { Test }\end{array}$ & NNK & LR & $\begin{array}{l}\text { Polynomi } \\
\text { al }\end{array}$ \\
\hline 1 Jan -30*Jan-2018 & 31/Jan/2018 & $\begin{array}{l}7.381 \\
\%\end{array}$ & $\begin{array}{l}17.36 \\
2 \\
\%\end{array}$ & $25.221 \%$ \\
\hline $\begin{array}{l}26 \\
30 * \text { January/2018 }\end{array}$ & $31 /$ Janu $* 2018$ & $\begin{array}{l}5.968 \\
\%\end{array}$ & $\begin{array}{l}17.07 \\
3 \\
\%\end{array}$ & $66.811 \%$ \\
\hline
\end{tabular}

Task 4-Reconstruction of misplaced statistics from observing Stations exploit conclusion Tree, Polynomial Model, and K/N/N (IoT Dataset-consequences)

Keeping up the exploratory structure seen beforehand, Tables 11- 13 demonstrate the execution mistake allowing for the II checking rank, primary isolated also behind next joined while utilizing the choice ranking with $\mathrm{K}$ - closest neighbors forecast reproduction.

It develops with the purpose of in every one of the investigations; the choice ranking display achieves the greatest forecast execution, while a polynomial representation amid an element of higher degree than the second brings more awful outcomes. As to traits effect on the exhibitions decency, designed for the choice hierarchy the family member stickiness mutually among the warmth decides best outcomes, whereas allowing for the hotness unaccompanied prompts an execution decay.

Table 11. job 4: misplaced data forecast blunder of the feeler feature $r_{-}$inc starting examine posting

Place: 173 Calculation Errors (Training: 1 January-30 January 2018)

\begin{tabular}{|l|l|l|l|}
\hline Things & D7T & K/N/N & Polynomial \\
\hline $\begin{array}{l}\text { BAS(r_inc + lat + lon } \\
+ \text { alt })\end{array}$ & & 65.22 & 469.78 \\
\hline BASE + Temp & 38.10 & 48.26 & 469.78 \\
\hline BASE + RH + Temp & 24.11 & 42.71 & 469.78 \\
\hline BASE + RH & 27.07 & 42.71 & 469.78 \\
\hline $\begin{array}{l}\text { BASE + RH + Temp } \\
\text { + Rain }\end{array}$ & 24.11 & 42.71 & 469.78 \\
\hline
\end{tabular}

Table 12. Task 4: Absent data calculation blunder of the antenna attribute

Place: 186-Guess Error (Instruction: 1 January-30/ January 2018)

\begin{tabular}{|l|l|l|l|}
\hline Features & D-T & K-N-N & Polynomial \\
\hline $\begin{array}{l}\text { BASE*_ } \\
\text { lon + alt })\end{array}$ & 117.802 & 107.17 & 526.33 \\
\hline BASE + Temp & 89.161 & 104.14 & 526.33 \\
\hline BASE + RH + Temp & 63.202 & 104.841 & 526.332 \\
\hline BASE + RH & 62.982 & 104.842 & 526.331 \\
\hline $\begin{array}{l}\text { BASE + RH + Temp + } \\
\text { Rain }\end{array}$ & 69.823 & 104.843 & 526.338 \\
\hline
\end{tabular}

Table 13. Mission 4: absent statistics guess blunder of the feeler characteristic $r_{-}$inc beginning equally monitor place 173 along with 186 via choice trees (D.T), K.N.N, as well as polynomial engine scholarship method on IoT Sensors dataset.

Position: 173 + 186Forecast Fault (training: 1January-30 January-2018)

\begin{tabular}{|c|c|c|c|}
\hline Reasons & D.T & K.N.N & Polynomial \\
\hline $\begin{array}{l}\text { BASE(r_inc + lat + } \\
\text { lon }+ \text { alt })\end{array}$ & $\begin{array}{l}68.7 \\
4\end{array}$ & 71.01 & 248.28 \\
\hline$\overline{\mathrm{BASE}}+$ Temp & $\begin{array}{l}86.0 \\
4\end{array}$ & 85.17 & 248.28 \\
\hline $\begin{array}{l}\text { BASE } \\
\text { Temp }\end{array}$ & $\begin{array}{l}39.5 \\
3\end{array}$ & 80.12 & 248.28 \\
\hline $\mathrm{BASE}+\mathrm{RH}$ & $\begin{array}{l}41.4 \\
4\end{array}$ & 80.12 & 248.28 \\
\hline $\begin{array}{l}\text { BASE + RH + } \\
\text { Temp + Rain }\end{array}$ & $\begin{array}{l}40.1 \\
2\end{array}$ & 80.12 & 248.28 \\
\hline
\end{tabular}

There encompass additionally be further expectation subundertakings, as in chore 3 , perform devoid of utilizing the cross-approval preparing method to keep up the worldly cognizance of information whilst creation esteem forecasts on them (Table 14); likewise this occasion, the mock-up with the intention of greatest occupation utilizing huge information interim for its preparation (DT) is surpassed by the other one (KNN), while once more, while thinking about not very many information in support of the preparation (4 existence) the polynomial individual is the somewhat improved decision $(9.37 \%$ versus $16.16 \%)$.

Table 14. Task 4: calculation mistake of the antenna characteristic $r_{-}$inc impending beginning equally 173 with 186 supervise position by means of conclusion tree,

$\mathrm{K}-\mathrm{N}-\mathrm{N}$, moreover polynomial weakening engine knowledge model taught among dissimilar time-sequence distance meant for the teaching on the IoT Sensors dataset.

Posting: 173 + 186 Calculation Mistake

\begin{tabular}{|c|c|c|c|c|}
\hline Education period & $\begin{array}{l}\text { Forecast } \\
\text { experiment }\end{array}$ & $\mathrm{D} * \mathrm{~T}$ & $\begin{array}{l}\mathrm{K} * \mathrm{~N} \\
* \mathrm{~N}\end{array}$ & $\begin{array}{l}\text { Polynomi } \\
\text { al }\end{array}$ \\
\hline January- & $31 * \operatorname{Jan} * 2018$ & 12.10 & 9.662 & 25.225 \\
\hline 30/*January 2018 & & 2 & & \\
\hline $\begin{array}{l}26 \quad \text { January- } \\
30 / * \text { January } \\
2018\end{array}$ & $\begin{array}{l}31 * \text { January/ } \\
2018\end{array}$ & $\begin{array}{l}29.37 \\
2\end{array}$ & 7.652 & 66.811 \\
\hline
\end{tabular}

Task 5- Recognition of defective supervise position through Analyzing Their Sensor principles(IoT Datasetconsequences)

Abusing the checking location characteristics height, longitude, moreover scope in the I.o.T Sensors dataset, the bunching dependent happening the Euclidean separation assembles bunches among comparative geographic qualities. In stand 15, there is a model amid a bunch completed by III checking location (ID = 394, 396, moreover 397) 
demonstrating the record of their $r$ _inc esteem along with its figured worldwide contrast; on the grounds that the difference-max computed on their $r$ inc characteristic incentive for June 2017 is towering (3.740

$-0.570=3.170$ ), likewise beginning an exact resistance edge of 30/40, it is conceivable that place 396 languished a blame over its sunlight based emission feeler since 9/June $/ 2017$

Table 15. Task 5: a bunch of III monitor posting everywhere the elevated charge of the disparity- max on the $r$ inc quality summit toward a hardware sensor subject starting June 2017 for the station 396.

$\mathbf{R}$ _inc (Station 394) $r \_i n c$ (position 396) $r \_$inc (Station 397)-Date_Time-Diff_Max

\begin{tabular}{|l|l|l|l|l|}
\hline 3.740 & 0.570 & 3.430 & $\begin{array}{l}9 \\
\text { June 2:00:00 p.m. }\end{array}$ & 3.170 \\
\hline 3.610 & 0.470 & 3.320 & $\begin{array}{l}14 \text { June 2017 } \\
\text { 2:00:00 p.m. }\end{array}$ & 3.140 \\
\hline
\end{tabular}

The association Index connecting 2 measurable factors is a metric with the aim of communicates a straight connection among them; specified two factual factors X furthermore Y, their relationship record is the Pearson creation- minute connection coefficient characterized in (9), as their covariance separated by the result of the average divergence of the II factors

$$
\rho_{X Y}=\frac{\sigma X Y}{\sigma_{X} \sigma_{Y}}, 1 \leq \rho_{X Y} \leq+1
$$

Anywhere $\sigma \mathrm{XY}$ is the covariance (a proportion of how a great deal the 2factors depend jointly) among $\mathrm{X}$ in addition to $\mathrm{Y}$ moreover $\sigma \mathrm{X}, \sigma \mathrm{Y}$ are the II normal divergence (factual scattering file, which is a gauge of the changeability).

The coefficient dependably accept morals somewhere in the range of -1 and 1 , while an esteem more prominent than +0.7 confirmations a solid neighborhood connection that container survive immediate (optimistic symbol) before backwards (unconstructive mark). The relationship lists of $n$ factors (or else individuality) canister survive introduced in a connection lattice, which is a tetragon grid of $n \times n$ measurement among the factors taking place the lines moreover on the segments. The lattice is balanced, that is, $\rho \mathrm{ji}=\rho \mathrm{ij}$ thus the coefficients lying on the principle corner to corner are 1 .

\section{VI.CONCLUSION}

The examination displayed in this work presents useful, modest, and simple to-create undertakings that are valuable to expand the profitability of an agrarian organization, extending the investigation of the savvy cultivate show; the innovative advancement in a meadow with the intention of wants manage as well as streamlining preserve truly add toward spare natural assets, regard the commerce also global laws, fulfill the shopper wants, as well as seek after monetary benefits. The three distinct information sources, with an uncommon eye on behalf of the IoT sensors dataset, include be distorted exploit machine learning methods moreover the additional typical measurable ones. The principal errand demonstrates so as to the figure of apple along with pear add up to harvest on the I stat dataset might be come to amid a neural system display through a win charge near $90 \%$, whilst in the second undertaking, it rises to facilitate pro the C.N.R logical information, polynomial prescient further more relapse replica are additional suitable bearing in mind the idea of the dataset.

Undertakings 3 moreover 4 in attendance a similar objective looked with changed machine learning techniques on an unadulterated IoT sensors dataset, demonstrating with the aim of the choice ranking show workings extremely glowing; with the intention of nearby are particular natural components originating from sensors equipment that influence the model exhibitions; and, besides, to transient prospect qualities among couple of past information can be anticipated utilizing measurable relapses. It can't be forgotten, in any case, that in situations where there are not very many information measurable models, for example, direct or polynomial that still keep up the best prescient exhibitions; also, the discovery of broken checking position in mission 5 productively utilizes a bunching of the posting dependent taking place their geographic area helpful to recognize equipment flaws.

The insightful frameworks created among mechanism education calculations (directed also non) need to oversee adaptation to non-critical failure and equipment breakdown expectation, and, along these lines, they require structuring of incorporated instruments, UIs, and machines that effortlessly adjust to a settings exposed to common occasions not as effectively unsurprising as the agrarian one. At long last, shrewd frameworks that give ongoing proposals and make long haul figures dependent on client decisions and inclinations must be examined and tried.

\section{REFERENCES}

1. Censimento Della Agricoltura. Available online: http://censimentoagricoltura.istat.it (accessed on 3 May 2018)

2. Classificazione Delle Attività Agricole. Available online: http://www.codiciateco.it/coltivazioni-agricoleproduzione-di-prodotti-animali--caccia-e-serviziconnessi/A-01 (accessed on 15 August 2018).

3. Sundmaeker, H.; Verdouw, C.; Wolfert, S.; PrezFreire, L. Internet of Food and Farm 2020. In Digitising the Industry-Internet of Things Connecting Physical, Digital and Virtual Worlds; River Publishers: Gistrup, Denmark, 2016; Volume 2.

4. Wolfert, S.; Ge, L.; Verdouw, C.; Bogaardt, M.-J. Big data in smart farming a review. Agric. Syst. 2017,153, 69-80. [CrossRef]

5. Biradarand, H.B.; Shabadi, L. Review on IoT based multidisciplinary models for smart farming. In Proceedings of the 2nd IEEE International Conference on Recent Trends in Electronics, Information Communication Technology (RTEICT), Bangalore, India, 19-20 May 2017; pp. 1923-1926.

6. Ramya, R.; Sandhya, C.; Shwetha, R. Smart farming systems using sensors. In Proceedings of the 2017 IEEE Technological Innovations in ICT for Agriculture and Rural Development (TIAR), Chennai, India, 7-8 April 2017; pp. 218-222.

7. Yoon, C.; Huh, M.; Kang, S.G.; Park, J.; Lee, C. Implement smart farm with IoT technology. In 
Proceedings of the 20th International Conference on Advanced Communication Technology (ICACT), Chuncheon-si Gangwon-do, Korea, 11-14 February 2018; pp. 749-752.

8. Arkeman, Y.; Utomo, H.A.; Wibawa, D.S. Design of web-based information system with green house gas analysis for palm oil biodiesel agroindustry. In Proceedings of the 3rd International Conference on Adaptive and Intelligent Agroindustry (ICAIA), Bogor, Indonesia, 3-4 August 2015; pp. 238-244.

9. Amanda, E.C.R.; Seminar, K.B.; Syukur, M.; Noguchi, R. Development of expert system for selecting tomato (Solanum lycopersicum L.) varieties. In Proceedings of the 3rd International Conference on Adaptive and Intelligent Agroindustry (ICAIA), Bogor, Indonesia, 3-4 August 2015; pp. 278-283.

10. Nurulhaq, N.Z.; Sitanggang, I.S. Sequential pattern mining on hotspot data in Riau province using the prefixspan algorithm. In Proceedings of the 3rd International Conference on Adaptive and Intelligent Agroindustry (ICAIA), Bogor, Indonesia, 3-4 August 2015; pp. 257-260.

11. Murphy, F.E.; Popovici, E.; Whelan, P.; Magno, M. Development of an heterogeneous wireless sensor network for instrumentation and analysis of beehives. In Proceedings of the 2015 IEEE International Instrumentation and Measurement Technology Conference (I2MTC), Pisa, Italy, 11-14 May 2015; pp. 346-351.

12. Saha, A.K.; Saha, J.; Ray, R.; Sircar, S.; Dutta, S.; Chattopadhyay, S.P.; Saha, H.N. Iot-based drone for improvement of crop quality in agricultural field. In Proceedings of the IEEE 8th Annual Computing and Communication Workshop and Conference (CCWC), Las Vegas, NV, USA, 8-10 January 2018; pp. 612-615.

13. Monsanto. Available online: https://monsanto.com/ (accessed on 3 May 2018).

14. Farmlink. Available online: https://farmlink.net/ (accessed on 3 May 2018).

15. Farmlogs. Available online: https://farmlogs.com/ (accessed on 3 May 2018)

16. Lesser, A. Big Data and Big Agriculture; Gigaom Research: San Francisco, CA, USA, 2014.

17. Patil, S.S.; Thorat, S.A. Early detection of grapes diseases using machine learning and IoT. In Proceedings of the 2nd International Conference on Cognitive Computing and Information Processing (CCIP), Mysore, India, 12-13 August 2016; pp. 1-5.

18. Truong, T.; Dinh, A.; Wahid, K. An IoT environmental data collection system for fungal detection in crop fields. In Proceedings of the IEEE 30th Canadian Conference on Electrical and Computer Engineering (CCECE), Windsor, ON, Canada, 30 April-3 May 2017; pp. 1-4.

19. Sarangdhar, A.A.; Pawar, V.R. Machine learning regression technique for cotton leaf disease detection and controlling using IoT. In Proceedings of the 2017 International Conference of Electronics, Communication and Aerospace Technology (ICECA), Coimbatore, India, 20-22 April 2017; Volume 2, pp. 449-454.

20. Satamraju, K.P.; Shaik, K.; Vellanki, N. Rural bridge: A novel system for smart and co-operative farming using IoT architecture. In Proceedings of the 2017 International Conference on Multimedia, Signal Processing and Communication Technologies (IMPACT), Aligarh, India, 24-26 November 2017; pp. 22-26

21. Kaishi, S.K. Big data analysis medical, agriculture, in the environmental field. Seibutsu-kogaku Kaishi 2014, 92, 92-93.

22. Istat-National Institute of Statistics/CC-BY-SA-3.0 Available online: dati.istat.it/ (accessed on 3 May 2018).
23. CNR-National Research Council/CC-BY-SA-3.0 Available online: http://data.cnr.it/site/data (accessed on 3 May 2018).

24. Industrial IoT Sensors Dataset. Unpublished data 2018.Junior, S.L.D.; Cecatto, J.R.; Fernandes, M.M.; Ribeiro, M.X. SeMiner: A Flexible Sequence Miner Method to Forecast Solar Time Series. Information 2018, 9, 8. [CrossRef]

25. Ma, L.; Gu, X.; Wang, B. Correction of Outliers in Temperature Time Series Based on Sliding Window Prediction in Meteorological Sensor Network Information 2017, 8, 60. 